\title{
Features of Knowledge Quality of University Students in Ukraine
}

\section{Viacheslav Oleksenko}

\author{
Department of Higher Mathematics, \\ National Technical University "Kharkiv Politechnical Institute", Ukraine \\ kafedra2012@rambler.ru
}

Keywords: educational class, features of knowledge quality, studactive class, university student.

\begin{abstract}
In a highly technological post-industrial society the quality of education is an important factor in providing such a level of life and professional competency of a person that would satisfy both the demands of an individual and the state. The quality of the whole higher education is influenced by the quality of students' knowledge which is acquired at educational classes. Development of studactive classes has brought forward the problem of research of their efficiency, in particular in the aspect of potential quality of knowledge. The results of the experiment are outlined, the main aim of which was to identify the effect of studactive classes on knowledge quality of university students. Monitoring of quality of students' knowledge at studactive classes is realized. It is revealed that students who were taught in a studactive way have better features of knowledge quality (fullness, deepness, system character, operative character and flexibility) comparing with those who were taught in a traditional way. It is proved that knowledge quality of university students can be improved through implementing studactive classes into the pedagogical process. The study was conducted in Ukraine.
\end{abstract}

\section{Introduction}

The world community has acknowledged that education, health and well-being of people are the main factors of their life quality. In many countries quality of education is a priority of the society development. The quality of education as an object of management is one of the important indices according to which the efficiency of the educational system of any state along with its management in the world practice is defined. The United Nations Organization compares the level of social and economic development of countries by the human development index. By that, one of the main indicators is namely the index of the educational activity.

Some scientists (V. Andrushchenko, O. Lyashenko and others) connect the problem of the education quality with development of the informative civilization of the 21 st century, where the outstripping development of a person, society intellect and education system becomes the dominant factor of the human progress.

The urgency of the topic is also stipulated by the fact that in highly technological postindustrial society the quality of knowledge is the main argument in providing such a level of life and professional competency of a person which would satisfy both the demands of an individual and demands of the state.

In the base of the definition of the education quality there is monitoring teaching quality through the assessment of conditions of the educational process and monitoring preparation quality - level assessment of acquired by students' knowledge, skills and habits. A great number of monitoring systems are implemented in the world such as educational indices of UNESCO. Besides, there are various world programmes of studying the level of acquired knowledge:

TIMSS - Trends in Mathematics and Science Study (mathematics and natural subjects);

PISA - The Programme for International Student Assessment (literacy in mathematics, reading, natural sciences and computer);

PIRLS - Progress in International Reading Literacy Study (reading literacy) etc.

An entirely different level of monitoring concerns knowledge quality of university students by studying specific subjects. The quality of the whole higher education depends on the quality of knowledge, skills and habits similarly to the quality of a specific device which depends on the 
quality of each of its mechanisms. So it is necessary to start with the fundamental bases, namely the student, educational class and quality of student knowledge at an educational class.

The article is dedicated to analysing knowledge quality of future specialists at educational classes, especially studactive ones [1].

Research questions

The study was guided by such research questions:

- What is the knowledge quality at studactive classes?

- Is there any difference between student knowledge acquired in a studactive and traditional way?

- What can be said about the features of knowledge quality at educational classes?

\section{Literature Review}

The theory of knowledge by philosopher John Locke was based on the mind model which likened ideas to words [2]. This analogy between language and thought served as the basis for a graphic knowledge conception in which the mind was treated as a table, a container with content that had to be stocked with something specific. The evolution of the notion "knowledge" from a classical theory of knowledge to a modern one is revealed in many scientific papers, in particular [2-5].

The theoretical and gnosiological analysis of scientific publications has proved that on the one hand scientists are interested in the given problem; on the other hand, there are no single meanings in definitions of "quality of education" and "quality of knowledge". In a simplified form all these definitions could be classified into wide and narrow ones. Among the wide ones there are philosophical or generalized definitions. The quality of education is interpreted as balanced conformity of the process, result and educational system itself to goals, conditions, norms and standards advanced by the society. The quality of higher education is a complex characteristic, which reflects a range and level of educational services given by the system of education according to interests of a person, society and state. It is a system category that encompasses the notions "quality of knowledge" and "quality of preparation" [6, p. 1016]. In the narrow meaning the quality of education is a list of demands with a specific sum total of indices. To our mind due to distinctions in interpretations, people estimate its quality in a different way. Still it is not the only reason.

We will interpret the quality of knowledge as correlation between types of knowledge (laws, theories etc.) and elements of content as well as levels of its mastering [7]. Differences in definitions of the notion "knowledge" are analyzed in [1]. Knowledge is a tool of thinking and changing the world [5]. The quality of knowledge depends on the level of a person's thinking ability. Aspects of thinking development of students of technical universities at educational classes are revealed in [8].

Individual work of students plays a great role in acquiring, fixing and enlarging knowledge, skills and habits. It develops initiative work, stimulates a creative approach to solving educational and professional tasks [5]. Therefore, the quality of student knowledge depends on organization of their individual work. Besides it is of paramount importance to have various scientific and educational information in class, which is found and delivered by the student himself. The research results in increasing performance of individual work of students and practical realization of such an activity at educational classes are considered in [9].

Individual work gains a significant meaning at a studactive class. It is defined as an educational class where a progredient active creative individual acquiring knowledge by students in coherence with self-reflexion, self-improvement and self-realization under the influence of collegiality, is realized. The difference is revealed between these types of classes and well-known lectures, practical and other classes. With the help of the method of mathematical statistics it is proved that studactive classes favour the level improvement of mastering knowledge by students [1]. 
At the same time in [1] only the fact is ascertained that the level of mastering student knowledge at studactive classes is increasing. Monitoring of student knowledge in conditions when a part of a class is held without a teacher being present has not been researched yet. The procedure of control of student knowledge which is acquired out-of-class has not been highlighted. It is not clear whether such control is held at all.

The technology of holding a studactive class which includes the procedure of control is researched in [10]. It is revealed that the efficiency of control at such an educational class directly depends on combining the controlling activity of a teacher and self-controlling as well as intercontrolling activity of students. A significant aspect of studactive classes is the analysis of their results. The skill to analyze one's own work is quite a difficult task to do. The main difficulty is to keep an objective nature of work. It is cleared up how to assess a student work in an objective way and stimulate his wish to study. Besides, it is explained how a future specialist's activity is assessed collectively and individually. Principles, functions and basic demands of assessment are analysed. It is emphasized that it is very important to have a self-check and inter-check not only in class but also in out-of-class conditions. Such monitoring of knowledge of university students is revealed that promotes the increase of objectivity of a mark and their assurance in a teacher's least subjectivity during control [10].

The quality of student knowledge at studactive classes has not been researched yet as well as its features: fullness, deepness, system character etc. It is expedient that along with the highlighted significant theoretical results there should be an experiment in monitoring the quality of student knowledge at studactive classes.

\section{Methodology}

The research is directed at revealing the effect of studactive classes on the knowledge quality of university students. National Technical University "Kharkiv Politechnical Institute" in Ukraine was chosen as the base of the research. The selection was held from the students of a day-time department of the mentioned university.

To make grounded conclusions on the base of data selection it is necessary that the selection is representative. According to the law of great numbers, the selection reflects parent population in the right way if it is realized at random. That is why the students were chosen in such a way that everyone had the same probability to be selected. As a result, a non-iterated representative selection from first-year students of National Technical University "Kharkiv Politechnical Institute" was obtained.

At the beginning of the experiment the preparation levels in the experimental and control groups practically did no differ. The students of the control groups were in a one-to-one manner put in correspondence with the students of the experimental groups according to their level of knowledge. The quantity of students in those groups was 25 people in each. The process of teaching in the control group was held in a traditional way, while in the experimental group it was held in a studactive way.

In [1] the stochastic variable $X$ characterizes the level of students' knowledge of the control groups, where teaching was held in a traditional way, and the stochastic variable $Y$ characterizes the level of students' knowledge of the experimental groups by its measurement after implementation of the worked-out studactive class. It is obtained that

$$
\mathrm{P}\left(\mathrm{x}_{\mathrm{i}}=0, \mathrm{y}_{\mathrm{i}}=1\right)>\mathrm{P}\left(\mathrm{x}_{\mathrm{i}}=1, \mathrm{y}_{\mathrm{i}}=0\right),
$$

where $i=1, \ldots, 328$. Through the method of mathematical statistics at the significance level of $5 \%$, it is ascertained that applying studactive classes in the educational process changes the level of mastering knowledge by students, moreover in the direction of increase.

Exactly this ascertained fact plays a key role in grounding the quantity of 25 students of the experimental group. The quality of students' knowledge is analyzed after holding studactive classes by means of comparison. If the percentage indices of knowledge quality are found out to be lower 
in the control group, then there are all grounds to state the following hypothesis. The knowledge quality of university students can be improved through implementation of studactive classes into the pedagogical process.

To check the hypothesis, the features of quality of students' knowledge are found and compared at educational classes during a semester in the control and experimental groups. They are fullness (the quantity of curriculum knowledge about the object of learning); deepness (the totality of connections and relations between knowledge, clear to students); system character (comprehension of place of knowledge in the structure of the scientific theory); operative character (skills to use knowledge in standard situations or situations of the same type); flexibility (skills to find optional ways to use knowledge in changeable conditions) [7]. The experimental and control groups were chosen in the same way, and the quantity of students in them was enlarged by 4 times. The students learnt the same material of the curriculum during a semester: the difference concerned the types of educational classes. By the traditional learning the teacher could check knowledge quality of students by giving tests or exams. By the studactive learning the teacher obtained data about student knowledge and skills every week or after each studactive class that allowed to react quickly and to correct the educational process accordingly.

\section{Discussions and Results}

We will reveal the results of the experiment, the main aim of which was to bring out the effect of studactive classes on the quality of knowledge of students of higher educational establishments. The experiment was held in natural conditions without breaking the logics and procedure of the educational process.

The experimental and control groups were sorted out in the appropriate way with similar original data. Let us define the quality of student knowledge in the experimental group before holding studactive classes as $\mathrm{M}$, and after them as $\mathrm{N}$. The quality of student knowledge in the control group during this period of studying will be defined as $\mathrm{K}$ and $\mathrm{L}$ correspondingly. All the students learnt the same unit of their curriculum during three weeks. Besides, the same text-books where recommended to them. Let $\mathrm{X}=\mathrm{N}-\mathrm{M}$ and $\mathrm{Y}=\mathrm{L}-\mathrm{K}$.

According to our research it was revealed that $\mathrm{X}>\mathrm{Y}$, while $\mathrm{X}-\mathrm{Y}=11 \%$. It turned out that the quality of studying the same educational material is higher by studactive classes.

On the base of this fact as well as the results of the article [1] we have made an assumption that knowledge quality of university students can be improved through introduction of studactive classes into the educational process. Hence there is a necessity to research features of quality of student knowledge during educational classes.

The deepness of knowledge was defined by correlation of a number of perceived connections by students to a number of those which exist and are to be perceived at a given stage of studying. Comprehension of knowledge was defined by understanding the character of connections between knowledge (differentiating between essential and non-essential connections, making out the mechanism of creating and displaying these connections, interpreting the bases of the acquired knowledge as well as the ways to use them and principles which serve as grounds for the ways of usage etc.). The results of the analysis (in percentage) are displayed in Fig. 1. 


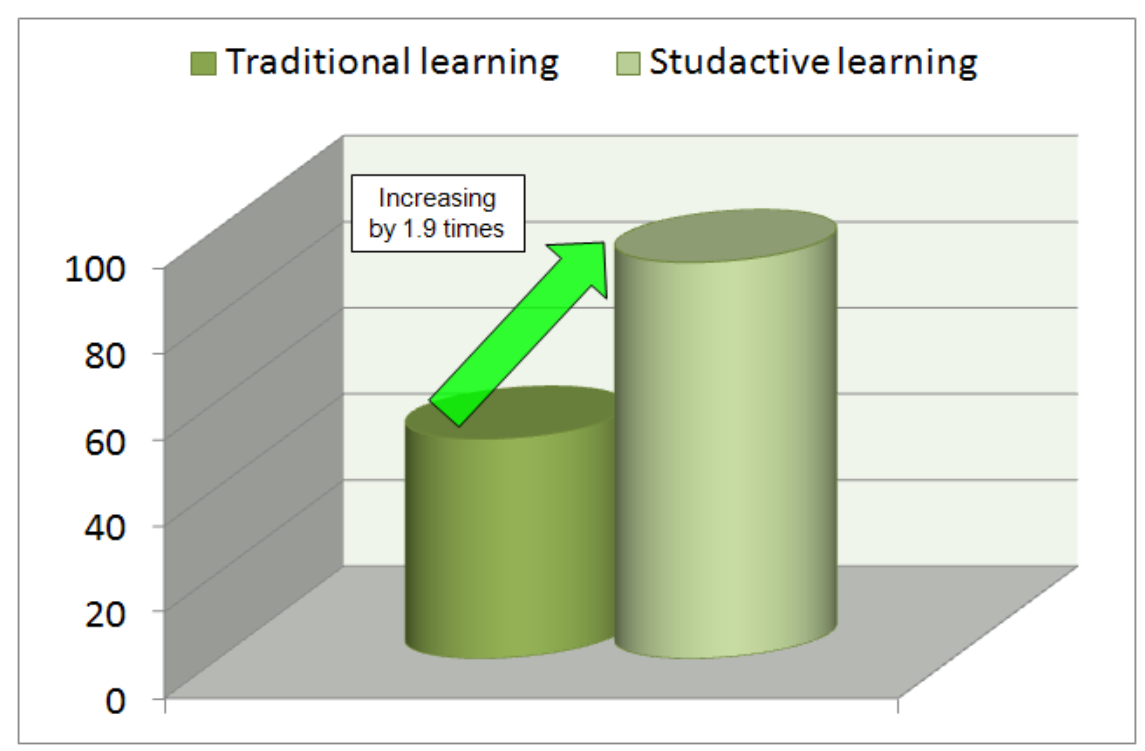

Figure 1. Analysis of knowledge deepness.

The operative character of knowledge was measured by dividing the quantity of correctly solved standard tasks or tasks of the same type during a definite stretch of time into their common quantity (Fig. 2).

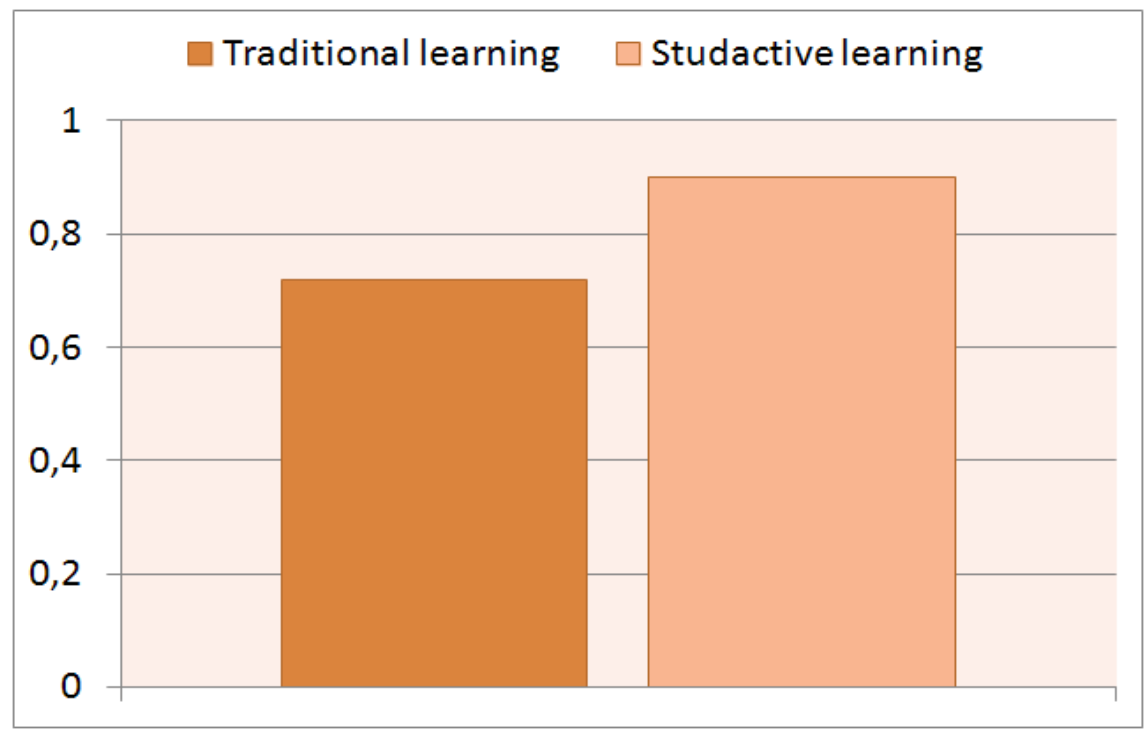

Figure 2. Analysis of indices of operative character of knowledge.

The fullness of knowledge was found by dividing the quantity of notions used by a student into the quantity of notions which was necessary to be used (Fig. 3). 


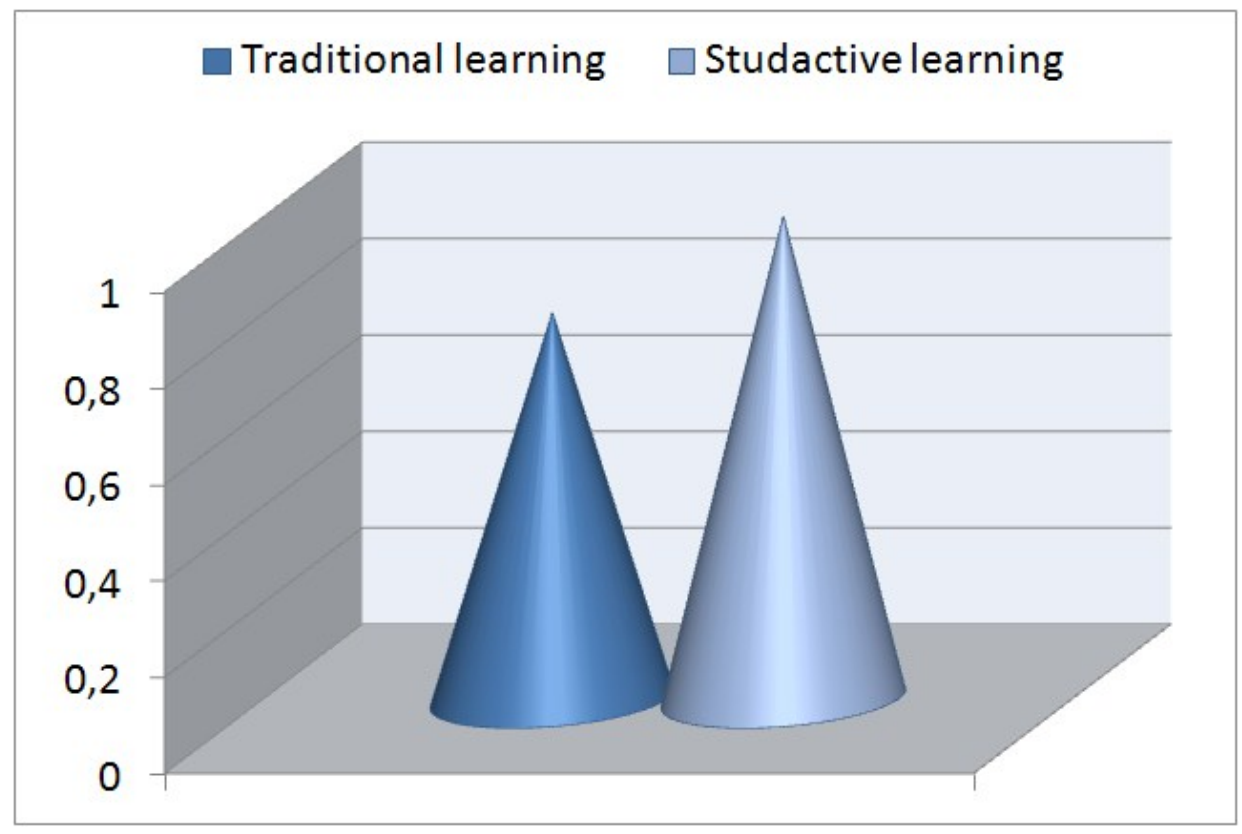

Figure 3. Analysis of indices of knowledge fullness.

The system character of knowledge was checked with the help of a scale that presupposed three levels: inter-definition, topical and inter-subject. The average meaning of the coefficient of the formed system knowledge of students in each group was calculated by the formula:

$$
S=\frac{\sum_{i=1}^{100} m_{i}}{m \cdot 100},
$$

where $m_{i}$ is a quantity of connections and correlations reproduced by a student; $m$ is a quantity of connections and correlations, which should be reproduced by a student.

The analysis of system character of knowledge of students who were taught in a studactive and traditional ways, allowed drawing a conclusion that correlation of the average meaning of coefficients of the formed system knowledge is more than 1:

$$
\frac{S(E)}{S(C)}>1
$$

where $S(E)$ concerns studactive learning and $S(C)$ - traditional one.

The flexibility of knowledge was calculated according to the quantity of the solved nonstandard creative tasks and individually elaborated problematic or professional situations. The result turned out to be impressive. A significant amount of students who were taught in a traditional way failed to solve such tasks. Flexibility of knowledge by studactive learning is by more than three times higher than flexibility of knowledge in the control group:

$$
\frac{F(E)}{F(C)}>3,
$$

where $F(E)$ is a quantity of students (in percentage) who were taught in a studactive way and succeeded in solving such tasks, $F(C)$ is a quantity of students (in percentage) who were taught in a traditional way and succeeded in solving such tasks.

\section{Conclusion}

Thus, all features of knowledge quality (fullness, deepness, system character, operative character, flexibility) of students of the experimental group taught in a studactive way turned out to be better. Moreover, the time of class-work decreased while the main content of the educational 
material was not changed. For all this the use of studactive classes influenced comprehension of knowledge to a higher extent. The students were able not only to fix connections between knowledge but also interpret them. The stated hypothesis of the research is verified and confirmed.

Such results are gained by following the technology of studactive classes, including powerful motivation of educational activity, permanent feedback, individual research, analysis and presentation of scientific and educational information. At studactive classes knowledge is obtained in a conscious and active way, based on research, beliefs and professional orientation. Responsibility is reached immediately. By such conditions future specialists realize what benefits are given to them and their society by knowledge. Consequently, the level of knowledge quality is increasing.

\section{References}

[1] V. Oleksenko, Innovative trend of acquiring and mastering knowledge by students, International Letters of Social and Humanistic Sciences. 65 (2015) 88-95.

[2] I. Hacking, Why does language matter to philosophy?, Cambridge University Press, Cambridge, 1975.

[3] MD Eddy, The shape of knowledge: children and the visual culture of literacy, Science in Context. 26(02) (2013) 215-245.

[4] Information on https://www.britannica.com.

[5] I.A. Kairov, Pedagogical dictionary, Moscow, 1, 1960. (in Russian)

[6] V.G. Kremen, Encyclopedia of education, Jurinkom Inter, Kiyv, Ukraine, 2008. (in Ukrainian)

[7] V. Oleksenko, Encyclopedia dictionary of distance learning, KP Printing House 13, Kharkiv, Ukraine, 2004. (in Ukrainian)

[8] V. Oleksenko, Aspects of thinking development by studying mathematics in technical universities, in: Proceeding "Means of Educational and Scientific and Research Work", Vol. 1, Kharkiv, Ukraine, 2000, pp. 50-54. (in Ukrainian)

[9] V. Oleksenko, Increasing efficiency of individual work of future specialists through distance learning, in: Problems of Modern Pedagogic Education. Ser.: Pedagogy and Psychology, Yalta, Ukraine, Vol. 11(2), 2006, pp. 272-281. (in Ukrainian)

[10] V. Oleksenko, Technology of mastering educational material in universities, World Scientific News. 42 (2016) 119-131. 